\title{
APLIKASI CHATBOT "MI3" UNTUK INFORMASI JURUSAN TEKNIK INFORMATIKA BERBASIS SISTEM PAKAR MENGGUNAKAN METODE FORWARD CHAINING
}

\author{
Zifora Nur Baiti, Fresy Nugroho, ST.,MT \\ Jurusan Teknik Informatika, Fakultas Saintek, UIN Maulana Malik Ibrahim Malang \\ $e$-mail: zhi_1mo3t@yahoo.com
}

\begin{abstract}
ABSTRAK
Chatbot adalah suatu aplikasi yang dirancang untuk berkomunikasi dengan mesin. Komunikasi ini membantu user dalam mencari sebuah informasi. Informasi yang diberikan bermacam-macam, seperti tentang akademik. Chatbot yang dibangun ini dikhususkan untuk sebuah informasi yang melingkupi jurusan Teknik Informatika UIN Maliki Malang. Chatbot ini dibangun dengan menerapkan sistem pakar menggunakan metode forward chianing. Metode forward chaining adalah metode yang digunakan untuk mencari kesimpulan dari fakta-fakta yang terkumpul. Metode forward chaining merupakan algoritma yang baik sebagai penyelesaian proses pencarian jawaban berdasarkan kata kunci dari pertanyaan user. Sistem kerja aplikasi ini adalah dengan memecah susunan kalimat menjadi kata kemudian dari kata tersebut oleh sistem akan dicari kunci yang membuat aplikasi dapat menjawab dengan benar. Dari hasil penelitian dengan menginputkan kalimat-kalimat yang berhubungan dan tidak dengan kategori, aplikasi ini mampu mengenali kata kunci pada kalimat-kalimat tersebut. Hal ini mengacu pada hasil pengujian yang didapatkan persentase sebesar Sangat Setuju 48,88\% dan Setuju 51,22\% dari 25 responden dengan beberapa kalimat masukan.
\end{abstract}

Kata Kunci: Informasi, Chatbot, sistem pakar, Forward Chaining

\section{PENDAHULUAN}

\subsection{Latar Belakang}

Manusia adalah makhluk paling mulia yang diciptakan oleh Tuhan. Yang membedakan sekaligus menjadikan manusia lebih istimewa jika dibandingkan dengan makhluk lainnya adalah manusia dibekali dengan akal, pikiran, perasaan, serta emosi. Salah satu aspek penting dari keistimewaan manusia tersebut adalah kecerdasan. Manusia dengan kecerdasannya yang tinggi mampu mengubah cara dan pola hidup yang dulu primitif menjadi sangat modern seperti sekarang. Manusia mampu membuat mesin-mesin yang memiliki kecerdasan sehingga dapat bekerja dengan sendirinya. Hal tersebut mulai dapat terwujud setelah diciptakannya sebuah mesin canggih yang bernama komputer.
Teknik yang memungkinkan mesin untuk berpikir dan dapat mengambil keputusan sendiri dinamakan kecerdasan buatan atau artificial intelligence (AI).

Dengan menggunakan kecerdasan buatan maka tidaklah mustahil akan ada mesin yang benar-benar mampu berpikir, bertindak, mendengar, melihat, dan berbicara layaknya manusia.

Sekarang, mesin atau 'alat hasil penemuan manusia' tidak lagi terfokus pada usaha menggantikan tenaga manusia untuk melakukan suatu pekerjaan, walaupun hal tersebut masih aktif dilakukan, alat tersebut dirancang untuk menggantikan otak manusia.

Perkembangan jaman ditandai dengan perkembangan 'otak elektronik'. Para praktisi di berbagai bidang menggunakan komputer untuk mempermudah kegiatan yang mereka 
lakukan dan mereka berlomba-lomba siapa yang memakai alat tercanggih, yang juga berarti memakai teknologi komputerisasi terpintar. Tujuan dari penelitian kecerdasan buatan adalah menciptakan mesin yang dapat berkomunikasi seperti layaknya manusia [ANOM4].

Sekarang ini, telah bermunculan chatbot-chatbot (sistem komputer yang berbasiskan bahasa alami atau natural language) lain yang telah beberapa langkah lebih maju dari ELIZA. Seperti chatbot yang diberi nama A.L.I.C.E, dan masih ada lagi yang lain. Semua chatbot yang bermunculan kemudian dan telah memenangkan Loebner Prize tersebut menggunakan kecerdasan buatan sebagai dasar aplikasi mereka. Walaupun telah banyak bermunculan chatbot-chatbot, tetapi penggunaan dari chatbot itu sendiri belum dimaksimalkan. Chatbot-chatbot tersebut cenderung hanya dimanfaatkan untuk memenangkan lomba atau alasan iseng lainnya.

Sebagai mahasiswa Teknik Informatika dengan bidang peminatan kecerdasan buatan, terdapat keinginan untuk mencoba menggali kemampuan chatbot agar terdapat kegunaan nyata dalam implementasinya. Dan untuk memaksimalkan kemampuan chatbot, ruang lingkup pembicaraannya harus dibatasi. Dengan alasan-alasan tersebut, peneliti bermaksud untuk mengadakan penelitian skripsi dengan judul "Aplikasi Chatbot "MI3" Untuk Informasi Jurusan Teknik Informatika Berbasis Sistem Pakar Dengan Metode Forward Chaining".

Chatting robot atau juga bisa disebut chatbot adalah salah satu kecanggihan yang nantinya menggantikan suatu pekerjaan manusia. Dengan sistem kerja yang dilakukan oleh chatbot, nantinya manusia ataupun user dapat dengan mudah mencari sebuah informasi yang diinginkan. Chatbot sekarang ini sudah mulai diterapkan di dalam sebuah website. Chatbot pertama ditulis oleh Joseph Weizenbaum, profesor MIT pada tahun 1966. Pada waktu itu tentu saja chatbot dibuat masih amat sangat sederhana. Chatbot ELIZA adalah program operasi dalam MAC time-sharing. Sistem di MIT yang membuat beberapa jenis bahasa alami percakapan antara manusia dan komputer. Kalimat masukan dianalisis berdasarkan aturan dekomposisi yang dipicu oleh kata kunci yang muncul dalam masukan teks. Chatbot yang terdapat di dalam website tersebut pada umumnya menjawab sebuah pertanyaan yang diajukan oleh user. Ruang lingkup yang dipertanyakan pun sudah dibatasi sehingga tidak keluar dari batas ruang lingkup yang ditentukan. Tetapi ada juga aplikasi chatbot yang tidak mempunyai batasan ruang lingkup, sehingga dalam hal menjawab sebuah pertanyaan sering tidak sesuai dengan apa yang ditanyakan oleh user.

Penerapan sebuah aplikasi chatbot dalam pendidikan dirasakan masih kurang. Belum dibutuhkannya aplikasi chatbot tersebut yang dijadikan dasar alasan belum diterapkannya aplikasi chatbot dalam pendidikan. Akan tetapi tidak semua kalangan menggunakan alasan tersebut dalam penerapan aplikasi chatbot. Website sebuah universitas dijadikan penerapan aplikasi chatbot untuk mengetahui informasi yang berkaitan dengan kampus. Dengan adanya chatbot yang difokuskan pada jurusan teknik informatika diharapkan dapat membantu mengurangi masalah ketidaktahuan user yang masih awam. Kebanyakan mahasiswa yang kurang informasi tentang jurusan teknik informatika dapat menyelesaikan ketidaktahuannya melalui chatbot ini.

\subsection{Rumusan Masalah}

Berdasarkan uraian diatas, maka dirumuskan masalah dari penelitian ini adalah bagaimana rancang bangun aplikasi chatbot "MI3" (Machine Intelligence of Informatics Information) yang mampu berkomunikasi dengan user.

\subsection{Batasan Masalah}

Dalam penelitian ini agar program yang dibuat mampu merespon pertanyaan ataupun komentar dari user dalam sebuah 
dialog, maka perlu dibuat batasan-batasan yang diberikan, yaitu:

a. Dialog dilakukan dalam bahasa Indonesia yang sesuai dengan EYD (Ejaan Yang Disempurnakan) seperti kata "sistem" bukan "sistim".

b. Chatbot "MI3" tidak melayani masukan dalam bentuk perhitungan matematis, dan tidak menanggapi masukan yang berupa karakter.

c. Chatbot "MI3" tidak membedakan lawan bicaranya berdasarkan identitas seperti jenis kelamin, umur, atau nama.

d. Topik Dialog dibatasi seputar informasi tentang laboratorium, matakuliah, ruang perkuliahan, waktu perkuliahan, dosen pengampu pada jurusan Teknik Informatika.

e. Aplikasi ini dibangun menggunakan Netlogo versi 4.1.3.

f. Aplikasi ini merupakan sebuah pemodelan Chatbot menggunakan Netlogo.

\section{Dasar Teori}

\subsection{Chatbot}

Program chatbot pertama ditulis oleh Joseph Weizenbaum, profesor MIT pada tahun 1966. Pada waktu itu tentu saja chatbot dibuat masih amat sangat sederhana. Meskipun perkembangan kecerdasan buatan saat ini sangat pesat dan canggih, namun chatbot tetap mempertahankan kedudukannya dalam dunia Artificial Intellegence [WEIZ66].

Chatbot adalah sebuah simulator percakapan yang berupa program komputer yang dapat berdialog dengan penggunanya dalam bahasa alami. Karena chatbot hanya sebuah program, dan bukan robot (chatbot tidak memiliki tubuh dan tidak memiliki mulut sehingga tidak dapat berbicara seperti manusia), maka yang dimaksud dengan dialog antar manusia sebagai pengguna dengan chatbot dilakukan dengan cara mengetik apa yang akan dibicarakan dan chatbot akan memberikan respon. Orang yang membuat dan mengembangkan program chatbot disebut bot master [RUDI05].

\subsection{Netlogo}

NetLogo adalah bahasa pemodelan yang dapat diprogram untuk mensimulasikan fenomena alam dan sosial. Bahasa pemodelan ini ditulis oleh Uri Wilensky pada tahun 1999. NetLogo sangat cocok untuk pemodelan sistem yang kompleks, yang dapat dikembangkan dari waktu ke waktu. Pemodel dapat memberikan instruksi kepada ratusan atau ribuan "agen", dimana operasi tiap agen bersifat independen. Kelebihan ini memungkinkan eksplorasi hubungan perilaku yang terjadi antar individu di tingkat mikro dan memodelkan pola yang muncul pada tingkat makro dari interaksi banyak individu [FRESS12].

\subsection{Sistem Pakar}

Expert System atau sistem pakar adalah suatu program yang bertindak sebagai penasehat atau konsultan pintar dengan mengambil pengetahuan yang disimpan dalam domain tertentu [SRI03]. Seorang pemakai yang belum berpengalaman dalam mendiagnosa suatu masalah dapat memecahkan masalah yang sulit dan mengambil keputusan yang benar.

Secara umum sistem pakar adalah sistem yang berusaha mengadopsi pengetahuan manusia ke komputer, agar komputer dapat menyelesaikan masalah seperti yang biasa dilakukan para ahli. Sistem pakar tidak untuk menggantikan kedudukan seorang pakar tetapi untuk memasyaratkan pengetahuan dan pengalaman pakar tersebut. Sistem pakar dikembangkan pertama kali oleh komunitas AI tahun 1960an. Sistem pakar yang pertama adalah General Purpose Problem Solver (GPS) yang dikembangkan oleh Newel Simon.

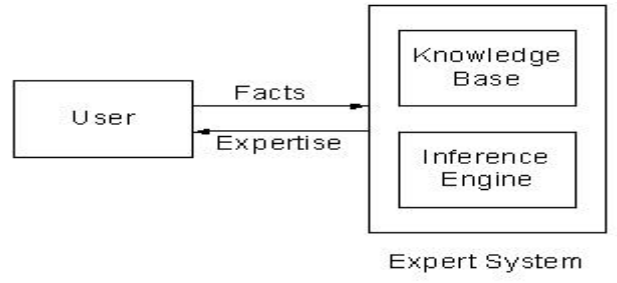

Gambar 1 Konsep Dasar Sistem Pakar 


\subsection{Forward Chaining}

Runut maju merupakan strategi pencarian yang memulai proses pencarian dari sekumpulan data atau fakta, dari datadata tersebut dicari suatu kesimpulan yang menjadi solusi dari permasalahan yang dihadapi. Mesin inferensi mencari kaidahkaidah dalam basis pengetahuan yang premisnya sesuai dengan data-data tersebut, kemudian dari kaidah-kaidah tersebut diperoleh suatu kesimpulan. Runut maju memulai proses pencarian dengan data sehingga strategi ini disebut juga data-driven [HERR12].

Operasi dari sistem forward chaining dimulai dengan memasukkan sekumpulan fakta yang diketahui ke dalam memori kerja (working memory), kemudian menurunkan fakta baru berdasarkan aturan yang premisnya cocok dengan fakta yang diketahui. Proses ini dilanjutkan sampai dengan mencapai gol atau tidak ada lagi aturan yang premisnya cocok dengan fakta yang diketahui [ANOM2].

\section{Basis Pengetahuan (Knowledge Base)}

Basis pengetahuan berisi pengtahuanpengetahuan dalam penyelesaian masalah. Ada 2 bentuk pendekatan basis pengetahuan [NOFI00] :

\section{- Penalaran Berbasis Aturan (Rule} Based Reasoning)

1. Pengetahuan dalam sistem pakar direpresentasikan dalam bentuk $\boldsymbol{I F}$ THEN atau dalam bentuk Production Rules.

2. Motor inferensi menentukan aturan awal (rule antecedents) yang sesuai.

- Sisi kiri harus cocok dengan fakta yang ada di memori kerja

3. Aturan yang sesuai ditempatkan di agenda dan dapat diaktivasi.

4. Aturan yang terdapat di agenda dapat diaktivasi.
a. Aktivasi aturan akan sisi kanan membangkitkan fakta baru di
b. Aktivasi dari satu aturan adalah bagian dari aktivasi aturan yang lain.

5. Contoh Basis Aturan :

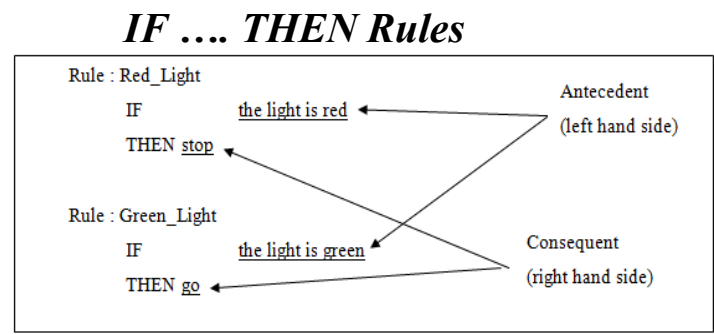

Gambar 2 If Then Rules

Production Rules

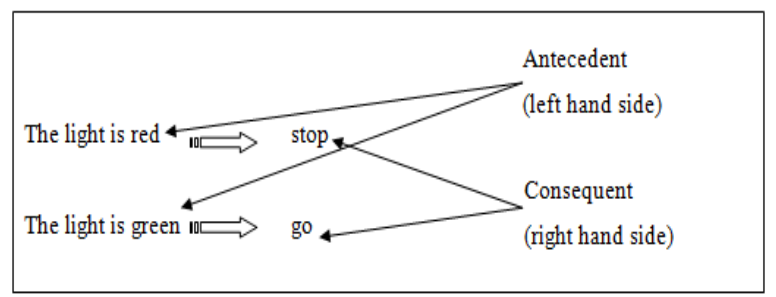

Gambar 3 Production Rules

\section{Rancangan Desain Sistem}

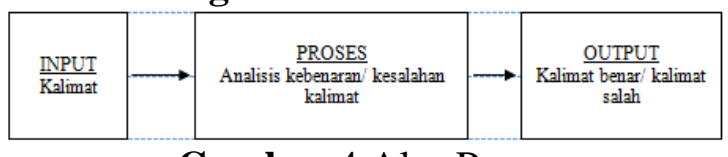

Gambar 4 Alur Perancangan

Tahap analisa sistem ini dilakukan untuk memenuhi kebutuhan sistem dalam hal:

a. Analisa masukan: meneliti masukan seperti apa yang mampu dibaca oleh sistem untuk kemudian dieksekusi.

b. Analisa keluaran: meneliti kemampuan keluaran sistem apakah sudah memenuhi kebutuhan yang diinginkan.

c. Analisa proses: meneliti jalannya sistem dalam mengeksekusi masukan hingga proses keluaran.

d. Analisa data: meneliti kelengkapan data yang dibutuhkan oleh sistem. 


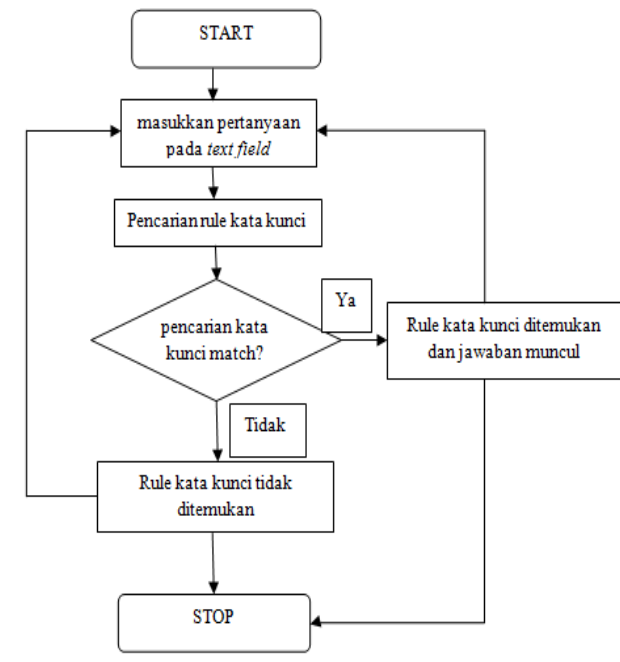

Gambar 5 Proses forward chaining

Proses forward chaining dimulai dengan user memasukkan informasi atau pertanyaan ke dalam text field yang sudah disediakan oleh aplikasi. Kemudian pertanyaan tersebut dipisah menjadi beberapa kata dan dicari kata kunci yang sesuai dengan yang ada pada aplikasi setelah kata kunci ditemukan maka aplikasi menjawab pertanyaan user dengan jawaban yang benar sedangkan jika aplikasi tidak dapat menemukan kata kunci maka jawaban muncul tetapi tidak berhubungan dengan pertanyaan dari user.

Kebutuhan Aplikasi

Aplikasi ini dibangun menggunakan Netlogo 4.3.1 sehingga terdapat kemudahan dalam membuat interface dengan menggunakan turtle shape editor yang sudah tersedia berbagai macam tools dalam Netlogo.

\section{HASIL DAN PEMBAHASAN}

\subsection{Uji Coba Metode}

Implementasi sistem pakar pada aplikasi chatbot ini terletak pada proses pencarian jawaban atas masukan pertanyaan dari user. Proses pertama terjadi ketika user memasukkan pertanyaan ke dalam kotak pertanyaan. Setelah itu masukan akan dicari berdasarkan kategori yang dipilih dan kata kunci yang ada di dalam pertanyaan. Berikut adalah Tabel hasil implementasi algoritma sistem pakar pada aplikasi chatbot.

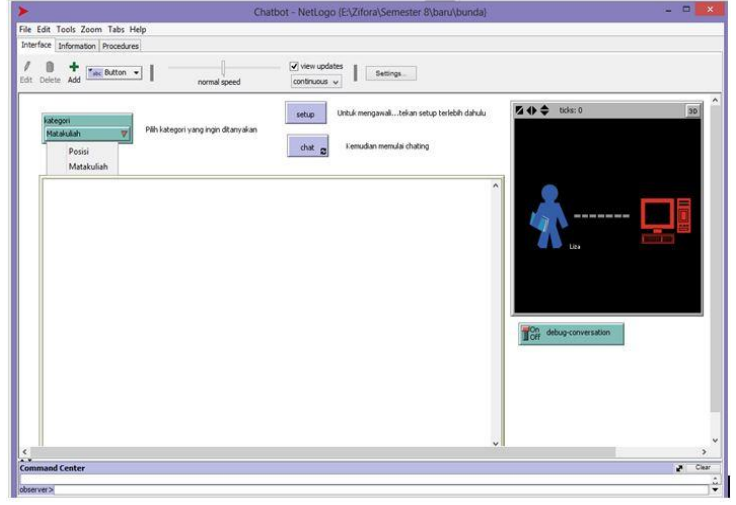

Gambar 6 Hasil chatbot

Tabel 1 Tabel Hasil Uji Coba

\begin{tabular}{|c|c|c|c|}
\hline No & $\begin{array}{c}\text { Masukan } \\
\text { Pertanyaan }\end{array}$ & $\begin{array}{c}\text { Kata } \\
\text { Kunci }\end{array}$ & Hasil \\
\hline 1. & $\begin{array}{l}\text { Jadwal hari } \\
\text { jumat apa? }\end{array}$ & $\begin{array}{l}\text { Jadwal hari } \\
\text { jumat }\end{array}$ & $\begin{array}{l}\text { - Organisasi dan } \\
\text { Arsitektur Komputer } \\
\text { - Grafika Komputer } \\
\text { - Keamanan dan } \\
\text { Jaringan Komputer } \\
\text { - Matematika Lanjut } \\
\text { - Pengantar Filsafat } \\
\text { Ilmu }\end{array}$ \\
\hline 2. & $\begin{array}{l}\text { Jadwal } \\
\text { matakuliah hari } \\
\text { jumat apa? }\end{array}$ & $\begin{array}{l}\text { jadwal }(.+) \\
\text { jumat }\end{array}$ & $\begin{array}{l}\text { - Organisasi dan } \\
\text { Arsitektur Komputer } \\
\text { - Grafika Komputer } \\
\text { - Keamanan dan } \\
\text { Jaringan Komputer } \\
\text { - Matematika Lanjut } \\
\text { - Pengantar Filsafat } \\
\text { Ilmu }\end{array}$ \\
\hline 3. & $\begin{array}{l}\text { Siapa nama } \\
\text { dosen matlan? }\end{array}$ & $\begin{array}{l}\text { Dosen } \\
\text { matlan }\end{array}$ & $\begin{array}{l}\text { Kamu Matlan kelas } \\
\text { apa? (Cantumkan } \\
\text { nama matkul + kelas } \\
\text { (Matlan kelas A)) }\end{array}$ \\
\hline 4. & $\begin{array}{l}\text { Saya matlan } \\
\text { kelas c }\end{array}$ & $\begin{array}{l}\text { Matlan } \\
\text { kelas c }\end{array}$ & $\begin{array}{l}\text { SUHARTONO, } \\
\text { M.Kom }\end{array}$ \\
\hline 5. & Kelas c & - & $\begin{array}{l}\text { Maaf pertanyaan anda } \\
\text { kurang jelas, silahkan } \\
\text { bertanya kembali }\end{array}$ \\
\hline 6. & $\begin{array}{l}\text { Dimana ruang } \\
\text { kuliah matlan? }\end{array}$ & $\begin{array}{l}\text { Ruang } \\
\text { kuliah } \\
\text { matlan }\end{array}$ & $\begin{array}{l}\text { Kamu Matlan kelas } \\
\text { apa? (Cantumkan } \\
\text { Ruang nama matkul + } \\
\text { kelas (Ruang Matlan } \\
\text { kelas A)) }\end{array}$ \\
\hline 7. & $\begin{array}{l}\text { Ruang kuliah } \\
\text { matlan dimana? }\end{array}$ & $\begin{array}{l}\text { Ruang } \\
\text { kuliah } \\
\text { matlan }\end{array}$ & $\begin{array}{l}\text { Kamu Matlan kelas } \\
\text { apa? (Cantumkan } \\
\text { Ruang nama matkul + } \\
\text { kelas (Ruang Matlan } \\
\text { kelas A)) }\end{array}$ \\
\hline 8. & $\begin{array}{l}\text { Ruang matlan } \\
\text { kelas c }\end{array}$ & $\begin{array}{l}\text { Ruang } \\
\text { matlan } \\
\text { kelas c }\end{array}$ & $\begin{array}{l}\text { Matlan Kelas C } \\
\text { Bertempat di Gedung } \\
\text { B. } 107\end{array}$ \\
\hline 9. & $\begin{array}{l}\text { Jam berapa } \\
\text { matlan ada } \\
\text { perkuliahan? }\end{array}$ & $\begin{array}{l}\text { Jam berapa } \\
\text { matlan }\end{array}$ & $\begin{array}{l}\text { Kamu Matlan kelas } \\
\text { apa? (Cantumkan } \\
\text { Pukul nama matkul + } \\
\text { kelas (Pukul Matlan } \\
\text { kelas A)) }\end{array}$ \\
\hline 10. & $\begin{array}{l}\text { Pukul matlan } \\
\text { kelas c }\end{array}$ & $\begin{array}{l}\text { Pukul } \\
\text { matlan } \\
\text { kelas c }\end{array}$ & $\begin{array}{l}\text { Matlan Kelas C Sabtu } \\
\text { Pukul 12.20-14.50 }\end{array}$ \\
\hline
\end{tabular}

Tahap ini dilakukan untuk mengetahui kemampuan aplikasi dalam menangani pertanyaan. Proses pengujian dilakukan sesuai dengan batasan masalah. Proses 
pengujian ini lebih terfokus pada bentuk susunan kalimat. Dalam proses pengujian ini kalimat yang dimasukkan berjumlah 40 kalimat.

Pengujian sistem ini dilakukan dengan menjalankan aplikasi chatting kemudian memasukkan kalimat dalam text field yang telah tersedia. Sebelumnya harus memilih kategori dan setup aplikasi.

Dari 40 kalimat sampel uji, didapatkan 37 kalimat yang teruji benar dalam susunan kalimat dan kata kunci.

Dengan menggunakan rumus berikut,

$$
\begin{gathered}
\text { presentase keberhasilan }= \\
\frac{\text { jumla } h \text { keber hasilan }}{\text { jumla } h \text { kalimat uji }} \times 100 \%
\end{gathered}
$$

Maka persentase keberhasilan aplikasi chatbot ini sebesar 92,5\%.

\subsection{PEMBAHASAN}

Dari hasil uji coba di atas, membuktikan bahwa metode forward chaining mampu menyelesaikan permasalahan untuk mengenali kalimat yang dimasukkan, apakah kalimat tersebut merupakan bentuk dari salah satu kata kunci atau bukan. Meskipun hampir mendekati sempurna, namun hasil persentase sebesar $92,5 \%$ juga membuktikan bahwa aplikasi ini masih memerlukan penyempurnaan. Kelengkapan kata kunci sangat berpengaruh pada keberhasilan aplikasi ini.

\section{KESIMPULAN}

Dari hasil implementasi dan uji coba yang telah peneliti lakukan, memperoleh kesimpulan bahwa algoritma Sistem Pakardengan metode forward chaining merupakan algoritma yang baik sebagai penyelesaian proses pencarian jawaban berdasarkan kata kunci dari pertanyaan user.

Aplikasi ini sangat cocok untuk media informasi, sebagaimana terlihat dari hasil uji coba prosentase sebesar $92 \%$. Dari hasil penelitian penulis menyimpulkan bahwa aplikasi ini sangat membantu mahasiswa sebagai media informasi jurusan Teknik Informatika.
6. DAFTAR PUSTAKA

[ANOM2] http://digilib.ittelkom.ac.id/ index.php?option=com_content $\&$ vie $\mathrm{w}=$ article\&id=677:res\&catid=13:rpl \&Itemid=14 diakses tanggal $27 \mathrm{Mei}$ 2013

[ANOM4]

library.binus.ac.id/...ac.../Bab1PS/20

07-2-00224-IF\%20BAB\%20I.ps diakses tanggal 15 November 2012

[NOFI00]

http://nofita_rismawati.staff.gunadar ma.ac.id/Downloads/files/29921/2Pendahuluan+ES.doc diakses tanggal 6 Januari 2013

[HERR12]

http://herriyance.trigunadharma.ac.id /wpcontent/uploads/2012/06/Bab4_AI.p df diakses tanggal 27 Mei 2013

[RUDI05] Rudiyanto, N. 2005. Perancangan dan Implementasi Perangkat Lunak Natural Language Processing Untuk Pengembangan Chatbot Berbahasa Indonesia. Skripsi. Universitas Komputer Indonesia (UNIKOM) Bandung.

[SRI03] Kusumadewi, S. 2003. Artificial Intelligence (Teknik dan Aplikasinya.Yogyakarta:GRAHA ILMU.

[WEIZ66] Weizenbaum, J. 1966. ELIZA-A computer program for the study of natural language communication between man and machine. Communicationsof the ACM 10.8: 36-45.

[FRESS12] Nugroho, Fressy. 2012. Tutorial Netlogo. Malang: UIN PRESS 